\title{
A formação docente na universidade e a resignificação do senso comum
}

\section{Teacher formation at the university and the resignification of common sense}

\author{
Maria Isabel da Cunha*
}

\begin{abstract}
RESUMO
Este texto se insere no campo da formação para a docência da educação superior e procura avançar a discussão baseada em teorias do conhecimento que valorizam o senso comum e sua relação com o cotidiano. Registra os desafios para esse campo e quer ampliar a compreensão e construção de algumas teses que possam fazer avançar os estudos sobre a docência na universidade. Procurando autores do campo da sociologia do conhecimento, o texto traz provocações que estimulam pesquisas e estudos que incorporem olhares distintos sobre o fenômeno. Aliando-se à corrente que valoriza o senso comum e as energias que circulam nos processos formativos, procura respostas teóricas que sustentem novas investigações. Bergmann \& Luckmann e Heller foram os atores preferenciais que levaram a outras contribuições. O intuito é provocar múltiplos olhares sobre a docência universitária e melhorar a qualidade da educação no país.

Palavras-chave: Docente da Educação Superior. Cultura docente. Prática pedagógica. Senso comum.
\end{abstract}

\footnotetext{
ABSTRACT

This text inserts itself in the field of formation to teaching on superior education and looks forward to make advances in the discussion based on theories of knowledge that values common sense and its relation with the everyday

* Universidade Federal de Pelotas. Programa de Pós-graduação em Educação. Pelotas, Rio Grande do Sul, Brasil. E-mail: cunhami@uol.com.br. http://orcid.org/0000-0003-4129-7755.
} 
life. It registers challenges to this field and wants to increase studies about teaching at the university. Looking for authors from sociology of knowledge, the text brings provocations that stimulate researches and studies which incorporate distinct views about the phenomena. Allying with the prevailing that values common sense and energies that surround formative processes, search for theoretical answers that sustain new investigations. Bergmann \& Luckmann and Heller were the preferential authors that took to other contributions. It aims to provoke multiple views on university teaching and improve the country's education quality.

Keywords: Higher Education Faculty. Teaching culture. Pedagogical practice. Common sense.

Os estudos sobre a docência universitária têm exigido um olhar preferencial sobre a especificidade deste fazer profissional que, ao mesmo tempo que se insere na categoria geral da profissão de professor, inclui condições especificas de exercício, próprias do espaço e tempo em que se situa.

Atuar na educação superior envolve práticas que se identificam com a docência em outros níveis de ensino, mas incluem outras dimensões e responsabilidades próprias da docência universitária, com especial destaque para a pesquisa e a extensão. Essa condição confere à profissão uma perspectiva de saberes múltiplos e interligados. Decorre de uma cultura historicamente consolidada que define práticas e estruturas de poder.

Temos recorrido à sociologia do conhecimento para aprofundar as questões sobre a docência na educação superior. Bergmann e Luckmann (1985) afirmam que sociologia do conhecimento trata das relações entre o pensamento humano e o contexto social dentro do qual surge. Ampliado, se poderia dizer que o conceito remete a um problema mais geral, o da determinação existencial. A sociologia do conhecimento tem sua raiz nos estudos de Marx que declara ser a consciência do homem determinada por seu ser social. O que interessa a Marx é que o pensamento humano funda-se na atividade humana, ou seja, o trabalho, no sentido amplo da palavra.

De formas distintas, Nietzsche acrescentou novas perspectivas sobre o pensamento humano como instrumento na luta pela sobrevivência e pelo poder, explorando o que o autor chama de "arte da desconfiança" que inclui o conceito de "falsa consciência" como condição necessária à vida. Tendo esses estudos como referência, Scheler analisou com profundidade a maneira em que o conhecimento humano é ordenado pela sociedade, o que significa 
que ele está ali a priori à experiência individual, fornecendo a esta sua ordem de significação.

Expressiva contribuição foi dada, também, por Robert Merton, importante sociólogo norte americano, que construiu um paradigma para a sociologia do conhecimento, aplicando os conceitos de funções manifestas e latentes à esfera da ideação, fazendo distinção entre funções conscientes, intencionais das ideias e funções inconscientes, não intencionais. O sociólogo ficou conhecido por ter cunhado a expressão "profecia autorrealizável", um conceito nevrálgico para a sociologia moderna que descreve o processo de alteração de um resultado final fático por força de uma crença ou expectativa, correta ou incorreta. Também explora o conceito de grupos de referência, onde entram em questão todos os grupos possíveis e categorias aos quais um indivíduo pertence, família, amigos, parentes, conhecidos, associações e organizações até categorias sociais, como status, classe ou gênero. O problema adquire ainda complexidade quando há múltiplos grupos de referência sendo levados em consideração simultaneamente. Nesses casos, segundo o autor, há uma interferência da identificação pessoal maior com um determinado grupo, bem como de fatores sócio estruturais e institucionais, na escolha de qual prevalecerá, por exemplo, nas situações de conflito ou contradição entre as condutas e valores prescritos.

Merton chama de socialização antecipada a adoção de grupos como referência dos quais o indivíduo sequer faz parte. Esta ocorre quando um ator social, desejando se tornar membro de um determinado grupo, passa a adotar valores e normas deste, em função do ímpeto, e à expectativa de conseguir um dia integrá-lo.

O espectro de autores e estudos em torno da sociologia do conhecimento se multiplica e se complexifica. Muitos aportes e visões teóricas favorecem a sustentação de análises que podem ser úteis para compreender o fenômeno da docência universitária.

Importante, também, parece ser a perspectiva teórica da vida cotidiana ou, como afirmam Bergmann e Luckmann, do conhecimento que dirige a conduta da vida diária (1985). Dizem os autores:

A realidade da vida cotidiana aparece já objetivada, antes da minha entrada em cena. A linguagem usada na vida cotidiana fornece as necessárias subjetivações e determina a ordem em que estas adquirem sentido e na qual a vida cotidiana ganha sentido para mim. (p. 38) 
Os autores defendem que é a linguagem que marca as coordenadas da vida e a dota de significação, pois esta não pode existir sem estar continuamente em interação e comunicação. A atitude natural de uma pessoa corresponde à dos outros, mesmo que eles tenham uma perspectiva diferente entre si. Os projetos de uns podem colidir como os dos demais, mas ambos convivem num mundo comum. O conhecimento do senso comum é o que se partilha com os outros nas rotinas normais, evidentes na vida cotidiana.

Outro conceito interessante para se analisar a docência universitária refere-se aos esquemas de tipificação que se realizam quando se está face a face com os demais professores ou com os estudantes. Defino o que o outro é pelo que é acessível a mim e o qualifico como "alegre", "estudioso", "vulnerável", "desinteressado" ou " simpático" etc. Esses sentimentos são, não raras as vezes, recíprocos. Mas estas tipificações da interação social tornam-se progressivamente anônimas à medida que se afastam da situação face a face. Correm o risco de criar generalizações transferíveis para outras situações. Então, todo o "desinteressado" pode ser "vulnerável" ou todo o "estudioso" ser "simpático". Nas palavras de Bergmann e Luckmann,

[...] a realidade social da vida cotidiana é, portanto, apreendida num contínuo de tipificações, que vão se tornando progressivamente anônimas à medida que se distanciam do aqui e agora, da situação face a face. $(1985$, p. 60)

A compreensão destes esquemas se tornam importantes num contexto de mudanças significativas no mundo acadêmico. A democratização e massificação da educação superior está trazendo públicos diferenciados para esse espaço de convivência com consequentes desafios para o sucesso e a permanência dos estudantes e bem-estar dos professores. Os campos semânticos são construídos pela experiência, tanto biográfica como histórica dos professores, e são objetivadas, conservadas e acumuladas, tornando-se o acervo social de conhecimento que eles carregam consigo ao exercer a profissão. Aí se instalam os preconceitos e estereótipos, mas também a possibilidade de mudanças nas representações e nos esquemas tipificadores.

É conveniente distinguir entre dois tipos gerais de conservação da realidade: a conservação rotineira e a conservação crítica. Para Bergmann e Luckmann (1985) a primeira destina-se a manter a realidade interiorizada da vida cotidiana e a segunda, a conservação em situações de crise. Elas se ma- 
nifestam e se corporificam nas rotinas, que é a essência da institucionalização e exigem a interação com os outros indivíduos.

É possível, pois, analisar o fenômeno da profissionalização dos docentes universitários nesse contexto. Os que iniciam a profissão trazem representações do senso comum importantes e que orientarão suas práticas na vida cotidiana. Dependendo do contexto e das experiências de vida e profissional, podem interiorizar mais a conservação rotineira do que a conservação crítica. Aliás, se não houver uma força mediadora para provocar a conservação crítica, certamente haverá maiores condições para se consolidar a conservação rotineira. Então cabe algumas indagações:

Como a teoria do campo da formação de professores vem se alimentando dos estudos da sociologia do conhecimento?

Como a concepção de senso comum vem sendo compreendida no campo da docência universitária?

Que possibilidades esta vertente teórica pode fortalecer estudos sobre a pedagogia universitária?

Para facilitar a compreensão dos conceitos aqui mencionados, organizamos um quadro com os principais autores a quem recorremos na fundamentação teórica desta reflexão.

RESSIGNIFICANDO O SENSO COMUM: CONTRIBUIÇÕES TEÓRICAS

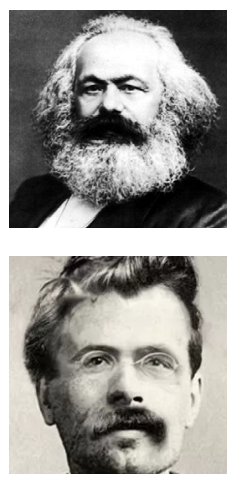

O pensamento humano funda-se na atividade humana: o trabalho (MARX, 2004)

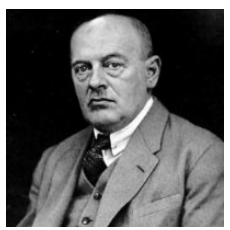

O pensamento humano é instrumento da luta pela sobrevivência e pelo poder. A arte da desconfiança. A falsa consciência (NIETZSCHE, 2013)

O conhecimento é ordenado pela sociedade. Está à priori à experiência individual. Fornece a ela sua ordem de significado (SCHELER, 2013) 


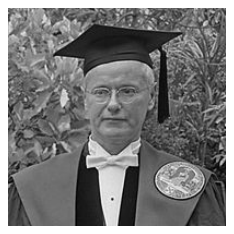

Os conceitos de formação manifesta (os conceitos) e latente ( o inconsciente) à esfera da ideação interferem na ação. Profecia autorealizável. Grupos de referência (MERTON, 1994).

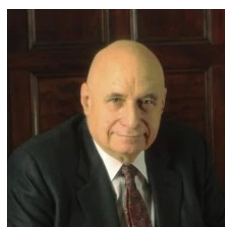

O conhecimento cotidiano dirige a conduta diária. A linguagem fornece a subjetivação e sentido. A realidade social é aprendida num conjunto de tipificações. Conservação rotineira e conservação crítica (BERGMANN \& LUCKMANN, 1985)

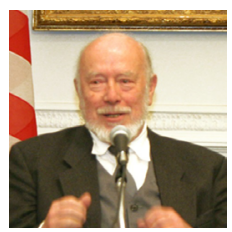

A realidade subjetiva depende sempre de estrutura específicas de plausibilidade, isto é, da base social específica e dos processos sociais exigidos pela sua conservação. A legitimação não é apenas uma questão de valores. Sempre implica, também, conhecimento (BERGMANN \& LUCKMANN, 1985).

\section{Em que a contribuição destes pensadores provoca o campo da docência universitária?}

Há, atualmente, um consenso de que a docência exige um repertório de saberes e conhecimentos que estimulam estratégias e técnicas pedagógicas para o enfrentamento da complexidade da profissão. Trata-se de uma práxis, atividade teoricamente fundamentada, pois toma-se a teoria, recria-se, inventa-se a prática enquanto sujeitos.

Porém, numa outra perspectiva, as teorias pós-estruturalistas chamam atenção para os dispositivos morais que a pedagogia propõe à docência. Trata-se de uma profissão constantemente vigiada e vigilante de uma compreensão de bem social. "Implica num modelo ideal de professor que funciona, ao mesmo tempo, como aspiração e critério de juízo para a avaliação de seu modo de ser e agir" (MARCELO GARCIA, 2002, p. 162). Os espaços acadêmicos funcionam como dispositivos que administram as subjetividades e as aspirações que incidem sobre a profissão.

O que se pode depreender é que a profissão de professor, caracterizada como um espaço de interação humana no contexto de estruturas de poder, é 
atingida pelas tensões ideológicas e morais que partilham tempos e espaços contraditórios. Nesse sentido, afasta-se de um referente universal de qualidade e depende das expectativas sociais e institucionais que sobre ela incidem.

Numa perspectiva mais pragmática, trata-se de uma profissão influenciada pelos contextos nacional e internacional e do campo científico e institucional no qual está inserida. Sua complexidade impacta a profissionalização tornando o professor responsável pelo desenvolvimento de processos formativos dos estudantes na educação superior e por produzir e disseminar conhecimento acadêmico em sua área. Assume posições institucionais reconhecidas pela cultura acadêmica e pelo seu estatuto profissional. Desenvolve e protagoniza ações de ensino, pesquisa e extensão em uma perspectiva indissociável. Responsabiliza-se pela validação das aprendizagens dos estudantes frente aos órgãos gestores, envolvendo saberes do seu campo de estudo, pedagógicos, éticos e culturais. Em uma visão ampliada, incorpora representações sociais historicamente construídas envolvendo as perspectivas de classe social e gênero, às expectativas em relação aos papeis institucionais e dos próprios docentes em um determinado tempo e espaço.

\begin{abstract}
A cultura docente se revela nos juízos de valor, nos rituais pedagógicos e nos discursos do campo científico da educação. Envolve as diferentes áreas do conhecimento e os espaços em que o professor produz sua ação pedagógica. Vincula-se a suas raízes e trajetórias de vida, mas também se modifica no cotejamento com as mudanças sociais e culturais do seu tempo (CUNHA, 2006, p. 364).
\end{abstract}

Vale ressaltar que há uma relação intrínseca da docência com a discência, pois o professor materializa o ato de ensinar com a participação e envolvimento dos estudantes. Isso significa que o ensino não se materializa desconectado da aprendizagem, intenção genuína da docência. A condição de ensinar pressupõe a interação humana e é atravessada pela perspectiva ética que envolve empatia e respeito aos saberes dos estudantes. Inclui uma relação de afeto com a matéria de ensino e habilidades pedagógicas que estimulem o desejo de aprender.

Essa condição para a docência pressupõe uma formação acadêmica em sua especialidade, consolidada na pós-graduação latu e stricto sensu, exigindo o domínio de saberes pedagógicos e o reconhecimento da prática de sua profissão e/ou da relação da sua matéria de ensino com um campo profissional, que revela e corresponde ao poder da profissão no interior da estrutura social. O campo profissional, articulado ao campo científico, impacta as práticas da 
profissão docente por incorporar decisões relacionadas à produção e distribuição do conhecimento a partir da macroestrutura social e econômica. Ou seja, as oscilações no campo das profissões interferem no perfil e desempenho do professor da educação superior.

O campo científico e profissional com seus valores e culturas se manifestam nas práticas e formas de atuação na academia. Podem atuar para a conservação ou transformação da realidade subjetiva. As representações sobre a docência e sobre a discência, seus fazeres e perfis se alternam nos diferentes espaços. Nesse contexto atuam forças ideológicas e culturais. Enquanto nas áreas das ciências exatas e da natureza predomina o rigor cientifico que se traduz pelo acumulo do conhecimento e perspectiva fundamentalmente cognitiva, nas áreas das ciências humanas o conhecimento válido passa pela contextualização e interpretação histórica e social. São condições que se expressam posteriormente na prática pedagógica do professor, envolvendo os rituais da aula, do currículo e da avaliação.

O que é importante, porém, é reconhecer a existência de um campo científico específico de saberes que precisam ser mobilizados para que a educação superior alcance sua dimensão política, social e cognitiva, que se constitui na pedagogia universitária. Na explicitação de Lucarelli (2000, p. 36),

[...] a pedagogia universitária é um campo polissêmico de produção e aplicação dos conhecimentos pedagógicos na educação superior. Reconhece distintos campos científicos dos quais toma referentes epistemológicos e culturais para definir suas bases e características. A pedagogia universitária é, também, um espaço de conexão de conhecimentos, subjetividades e culturas que exige um conteúdo científico, tecnológico ou artístico altamente especializado e orientado para a formação de uma profissão.

Pressupõe, especialmente,

[...] conhecimentos no âmbito do currículo e da prática pedagógica que incluam formas de ensinar e de aprender. Incide sobre as teorias e as práticas de formação de professores e dos estudantes da educação superior. Articula as dimensões do ensino e da pesquisa nos lugares e espaços de formação. Pode envolver uma condição institucional, considerando-se como pedagógico o conjunto de processos vividos no âmbito acadêmico (CUNHA, 2008, p. 321). 
Sendo um campo científico em fase de legitimação, a pedagogia universitária tem estimulado, em muitos países, estudos e pesquisas que procuram lhe dar consistência teórica e, ao mesmo tempo, sentido social e prático.

\section{Encaminhando estudos e pesquisas}

As reflexões teóricas aqui apresentadas estimulam uma análise original da condição do docente da educação superior, a partir das contribuições da sociologia do conhecimento. Essa iniciativa quer ampliar os estudos prescritivos e compreender as condições de conservação e produção de práticas docentes nos diferentes campos científicos que atuam na Universidade.

Alguns estudos (CUNHA, 2008) chamaram a atenção para o fato de que, na educação superior, temos múltiplas pedagogias, tendo em vista os valores do campo cientifico que as sustentam. Assim, ser professor de física pode incluir compreensões distintas sobre a docência, se comparadas como um professor de psicologia ou de clínica médica. Estas compreensões se materializam no que ensinar, no como organizar suas aulas, na valorização de atitudes dos estudantes, na avaliação da aprendizagem.

Entretanto essas filiações podem ser aprofundadas na perspectiva de compreender a relação da docência com a cultura profissional e com os valores que a sustentam. Trata-se de explicitar o que se instala nas representações de docência de um determinado campo profissional ou científico e que se revela nas práticas que institui um senso comum entre os seus professores.

Em um estudo que realizamos há mais de duas décadas (CUNHA e LEITE, 1996), explicitávamos as relações de poder entre a sociedade e as decisões que se toma no âmbito da universidade. Muitas delas, ainda que não sejam conscientemente percebidas, estão definidas no âmbito das profissões no contexto da sociedade capitalista que assume o conhecimento como instrumento de poder e de geração de capital.

As carreiras universitárias não têm o mesmo prestigio. Alguns cursos são mais valorizados do que outros. E as razões não são epistemológicas e sim econômicas; a sociedade é que define o valor de mercado do conhecimento e essas representações formam o senso comum da profissão, entendido como uma perspectiva naturalizada nas práticas cotidianas do processo de ensinar e aprender.

Por muito tempo a pedagogia da educação superior não se pautou por essa condição. Tanto a vertente baseada na racionalidade técnica como na que 
tomava a base psicologista do ensino não percebia o contexto cultural das diferentes carreiras, atingidas pelas estruturas de poder reguladoras da sociedade. Esse contexto naturaliza as formas de agir e de pensar dos professores que se constituem num senso comum enraizado no imaginário da corporação.

O que estamos defendendo é a importância da pedagogia universitária voltar-se para si e preocupar-se com estas questões. Abandonar as práticas prescritivas e desconectadas dos valores e estruturas dos campos profissionais. Pesquisá-los, compreendê-los e potencializá-los nas estratégias de formação e de qualificação do ensino. Uma prática formativa que esteja imersa nos campos de formação e ação dos docentes, fazendo vir à tona as culturas como ponto de partida e de chegada da reflexão. É importante recuperar a contribuição de Merton (1994) através dos conceitos de funções manifestas e latentes à esfera da ideação, fazendo distinção entre funções conscientes, intencionais das ideias e funções inconscientes, não intencionais. Também valorizar a perspectiva da "profecia autorrealizável", baseada em crenças ou expectativas incorporadas pelos sujeitos ou a importância dos grupos de referência, que incluem as organizações e categorias sociais, como status, classe ou gênero. Compreender que há uma socialização antecipada vinculada aos grupos de referência aos quais o indivíduo deseja fazer parte.

É importante, também, levar em conta o alerta feito por Bergmann e Luckmann (1985), que reforçam o significado da realidade social da vida cotidiana, formando um conjunto de tipificações que o indivíduo vai incorporando progressivamente.

Há diferenças explicitas entre as culturas docentes de professores da área das ciências humanas e das ciências exatas, que também se mostram distintas entre os cursos de profissões liberais e os de trabalho assalariado. Médicos e enfermeiros atuam no mesmo campo científico, mas são atingidos por lógicas de poder distintas presentes no mundo do trabalho. São fenômenos que interferem nas decisões pedagógicas e no trabalho docente.

O que estamos defendendo é uma posição que inclua a valorização do senso comum na perspectiva de Heller. Lembra Guimarães (2002) que na visão helleriana,

a vida cotidiana é a constituição e reprodução do próprio indivíduo e consequentemente da própria sociedade, através das objetivações. O processo de objetivação se caracteriza por essa reprodução, que não ocorre do nada para se efetivar, ela pressupõe uma ação do homem sobre o objeto, transformando-o para seu uso e benefício (p. 14). 
Nessa perspectiva, a analogia é uma característica que se manifesta para manter a repetição de um mesmo procedimento. Se o professor teve êxito na resolução e um problema, tenderá a aplicar a mesma estratégia em outra situação similar. Neste sentido, a analogia se relaciona com os juízos provisórios, pois ao não considerar uma crítica da ação, pode manter um padrão de comportamento preestabelecido e preconceituoso. É a utilização de um saber da prática de forma universal, ou seja, para resolver outras situações enfrentadas, uma vez que esta tenha dado certo ou signifique sucesso nos resultados almejados. Os juízos provisórios são assim considerados porque não possuem nenhuma teoria que os sustentem; são pensamentos empíricos baseados na experiência cotidiana e social das pessoas, uma vez que a prática os confirma como verdadeiros.

Como afirma Arruda (2002), "a base desses juízos é o senso comum, é um pensamento corriqueiro que não é 'conhecedor de causa'. Ele é determinado pelas experiências diárias, pela convivência com grupos que compartilham de um mesmo juízo provisório" (p. 76).

Vale lembrar que para Heller os juízos provisórios podem ser de dois tipos: os juízos ultrageneralizadores e os preconceitos. A característica básica que os diferencia é que o primeiro está baseado na confiança e o segundo no preceito da fé. Ambos, entretanto, estão presentes nas tomadas de decisão na lida profissional.

Em sendo o saber inacabado e historicamente produzido, vale repensar o confronto entre o "saber sistematizado" e o "saber cotidiano", este último podendo ser entendido como a soma de nossos conhecimentos sobre a realidade que utilizamos de um modo efetivo na vida cotidiana de modo mais heterogêneo. (HELLER, 1987).

Levando em conta que a autora considera a "vida cotidiana" como sendo "a vida do homem inteiro", é nela que se desenvolve toda a característica física, social e psicológica e também em que o homem exercita todas as suas habilidades, capacidades e paixões, como lembra Arruda (2002).

Estas considerações estimulam reflexões, pois sendo o saber inacabado e historicamente produzido, vale repensar o confronto entre o "saber sistematizado" e o "saber cotidiano", este último podendo ser entendido como a soma de nossos conhecimentos sobre a realidade que utilizamos de um modo efetivo na vida cotidiana de forma mais heterogênea. (HELLER, 1987).

Trazer os aportes da sociologia do conhecimento e a perspectiva helleriana sobre a relação do saber cotidiano com os processos de subjetivação que incidem sobre a prática docente pode inspirar desdobramentos para o campo da formação dos professores.

Certamente esse é um diálogo a ser ampliado, numa compreensão ana- 
lítica que aprofunde seus pressupostos. As reflexões aqui registradas querem ser provocadoras de perspectivas alternativas que incidam sobre a docência e os contextos de sua produção. Pode servir para questionar práticas ou repensar dispositivos que nos façam avançar nesse intento.

\section{REFERÊNCIAS}

ARRUDA, M. P. O papel social do professor universitário. In: GUIMARÃES, Gleny Duro (org.). Aspectos da teoria do cotidiano. Agnes Heller em perspectiva. Porto Alegre: EDIPUCRS, 2002.

BERGMANN, P.; LUCKMANN, T. A construção Social da Realidade. Petrópolis: Editora VOZES, 1985.

CUNHA, M. I. da. Pedagogia universitária e os desafios da produção do conhecimento. IN: BROILO, C. CUNHA, M. I. da. Pedagogia Universitária e produção do conhecimento. Porto Alegre: EDIPCRS, 2008. p. 29-36.

. In: MOROSINI, M. (org.) Enciclopédia da Pedagogia Universitária. Vol. 2. MEC/INEP/RIES, 2006.

CUNHA, M. I. da; LEITE, D. B. Decisões Pedagógicas e estruturas de poder na universidade. Campinas: Papirus, 1996.

GUIMARÃES, G. D. (org.). Aspectos da teoria do cotidiano. Agnes Heller em perspectiva. Porto Alegre: EDIPUCRS, 2002.

HELLER, A. Sociologia de la vida cotidiana. Barcelona: Península, 1987.

KELCHTERMANS, G. O comprometimento profissional para além do contrato: a auto-compreensão, vulnerabilidade e reflexão dos professores. In: FLORES, M. A.; SIMÃO, A. M. Aprendizagem e desenvolvimento profissional de professores: contextos e perspectivas. Manguakde/Portugal, Edições Pedagogo, 2009. p. 61-98.

LUCARELLI, E. El asesor pedagógico em la universidad. De la teoria pedagógica a la práctica en la formación. Buenos Aires: Paidos, 2000.

MARCELO GARCIA, C. Formação de professores. Para uma mudança educativa. Porto: Porto Editora, 2002.

MARX, K. Manuscritos econômico-filosóficos. São Paulo: Boitempo, 2004.

MERTON, R. K. A Life of Learning. Charles Homer Haskins, 1994. 
NIETZSCHE, F. A genealogia da Moral e a vontade do poder. Curitiba: Editora Escala. 2013.

SCHELER, M. A posição do homem no cosmos. Rio de Janeiro: Forense Universitária. 2003.

Texto recebido em 23 de maio de 2019.

Texto aprovado em 28 de maio de 2019. 